\title{
O movimento de Educação para Todos: a escolarização básica como retórica na formação do trabalhador $^{1}$
}

\author{
Francisca Helena de Oliveira Holanda \\ Professora da Universidade Estadual do Ceará e da FVJ/CE \\ Mestre em Educação pela Universidade Federal do Ceará \\ Maria Cleide da Silva Barroso \\ Professora do Instituto Federal de Educação, Ciência e Tecnologia do Ceará e da FVJ/CE \\ Mestre em Educação pela Universidade Federal do Ceará
}

\section{Resumo}

O artigo trata de uma crítica ao Programa de Educação para Todos, sob a organização do Banco Mundial, impõe um amplo programa de reestruturação dos sistemas nacionais de ensino, priorizando a universalização da educação básica. Esse ideário de educação tem sua gênese a partir da ascensão da burguesia ao poder, determinando um novo modo de produção: o sistema capitalista. Assim, a formação do trabalhador inclui aprendizagens úteis e adquiridas fora do trabalho. No caso brasileiro, as reformas educacionais constituem um pacto social para impulsionar o desenvolvimento econômico e a redução da pobreza numa economia sustentável.

Palavras-chave: Educação para Todos; Escolarização; Banco Mundial.

\section{Resumén}

El artículo hace una crítica al Programa de Educación para Todos, bajo la organización del Banco Mundial, imponiendo un amplio programa de remodelación de los sistemas nacionales de enseñanza, priorizando la universalización da la educación básica. Ese ideario de educación tiene su génesis a partir del ascenso da burguesía al poder, determinando un nuevo modo de producción: el sistema capitalista. De esa forma, la formación del trabajador incluye los aprendizajes útiles y logrados fuera del trabajo. En el caso brasileño, las reformas educacionales constituyen un pacto social para impulsar el desarrollo económico y la reducción de la pobreza en una economía sustentable.

Palabras claves: Educación para Todos; Escolarización; Banco Mundial.

${ }^{1} \mathrm{O}$ presente texto deriva da pesquisa "Universalizar o ensino e reproduzir o capital: os fundamentos do Movimento de Educação para Todos na perspectiva da crítica marxista”, CNPq, ligado ao Instituto de Pesquisa do Movimento Operário-IMO. 
preendemos que os homens, elevados à condição de seres
sociais, saltaram na escala de desenvolvimento a partir da
mediação homem/natureza, imprimindo uma atividade humanizadora. Na perspectiva da reprodução social, a centralidade do trabalho, se constitui como fundamento ontológico, pelo qual se ergue às esferas da sociabilidade, em que o trabalho na sua dimensão ontológica por mais simples que seja, está relacionado com a totalidade social. Nessa direção, conscientes de que a realidade está embotada pelos condicionantes históricos que os determinam, a pesquisa, toma como fundamento o construto teórico inaugurado por Karl Marx e resgatado por George Lukács, cujo processo de investigação caracteriza-se por categorias onto-históricas e filosóficas. Sendo assim, só é possível apreender um objeto de estudo se o diagnosticarmos dentro do complexo que compõe a totalidade social.

Nesse sentido, o referencial marxiano constitui a teoria que melhor explica a realidade social, pois não se reduz a esclarecer passivamente a história, já que esta não é produto da vontade de deuses a época em que se predominava a visão cosmológica e mística ou de algum princípio ahistórico que buscava explicar a realidade, mas da atividade concreta do mundo dos homens.

Todavia, a práxis que os homens vivenciam é dicotomizada pelas relações históricas construídas pelos próprios homens, fincadas na sociabilidade de classes e na divisão do trabalho. Nesse sentido, objetivamos apreender o movimento do ser social em função da superação do capitalismo para além da base que fundamenta a sociedade de classes. Assim sendo, Marx deixa essa concepção bem clara quando declara: “Os filósofos têm apenas interpretado o mundo de forma diferente, o que importa é mudá-lo” (Marx apud Labica, 1987, p. 164).

Com efeito, dado à complexidade do objeto, sua aparência é fenomênica e igual, por isso permitimo-nos o seu desvelamento. Cabe destacar aqui, que a perspectiva marxiana exige a captura do objeto estudado em seu movimento e integridade, o que não é perceptível no 
imediatismo do cotidiano, daí a necessidade da ciência para conhecer a verdade do objeto, pois "toda ciência seria supérflua se houvesse coincidência imediata entre aparência e a essência das coisas” (MARX, 2008, p. 1080). Sendo assim, Kosik (2002, p. 18) afirma que:

O conhecimento se realiza como separação de fenômeno e essência, do que é secundário e do que é essencial, já que só através dessa separação se pode mostrar a sua coerência interna, e com isso, o caráter específico da coisa. Neste processo, o secundário não é deixado de lado como irreal ou menos real, mas revela seu caráter fenomênico ou secundário mediante a demonstração de sua verdade na essência da coisa.

Por conseguinte, partimos da concepção de que a história da existência do ser social traz a gênese ontológica da categoria trabalho. Pela sua atividade produtiva, o homem se objetiva e elabora toda uma estrutura existencial. É no ato efetivo do trabalho que o homem torna-se ser social, parte estruturante dos atos desenvolvidos no tecido da totalidade social na firme busca contínua de atender suas necessidades de sobrevivência. Como bem afirmou Marx (1985, p. 50),

[...] como criador de valores de uso, como trabalho útil, é o trabalho, por isso, uma condição de existência do homem, independente de todas as formas de sociedade, eterna necessidade natural de mediação do metabolismo entre o homem e a natureza e, portanto, da vida humana.

Assim, na esteira da perspectiva ontológica do trabalho, compreendemos que todas as demais categorias ali contidas já têm em sua natureza um caráter social, ou seja, históricas. As suas características e modos de efetivar-se desenvolveram-se somente no ser social já plenamente constituído. Lukács (1981, p. 3 - 4) acrescenta:

Somente o trabalho tem, como sua essência ontológica, um claro caráter intermediário: ele é, essencialmente, uma interrelação entre homem (sociedade) e natureza, tanto com a natureza inorgânica (utensílios, matéria-prima, objeto do trabalho, etc.) como orgânica interrelação que pode até estar situada em pontos determinados da série a que nos referimos, mas antes de mais nada assinala a passagem, no homem que trabalha, do ser meramente biológico ao ser social [...]. No trabalho estão gravadas in nuce todas as determinações que, 
como veremos, constituem a essência de tudo que é novo no ser social. Deste modo, o trabalho pode ser considerado o fenômeno originário, o modelo.

Por sua vez, a busca contínua no processo de produção e reprodução da vida, a natureza humanizada, através do trabalho e pela perpetuação de sua existência, o ser social cria e renova as próprias possibilidades da sua reprodução. É no trabalho, ato efetivo, portanto, resultado de um pôr teleológico (prévia ideação), que o ser social tem organizado sua consciência estabelecendo finalidade. Assim, o produto de sua ação materializado constitui algo que não existia na natureza, o qual entendendo que tal fenômeno não se encontra nas outras formas biológicas da natureza.

Ademais, para nossa compreensão, a análise da gênese da vida, da esfera biológica, evidencia que o que distingue a matéria orgânica da matéria inorgânica é que a primeira caracteriza-se por um ininterrupto processo de reposição do mesmo, por exemplo, uma montanha terá a mesma composição mineral das planícies, e dos montes e a segunda matéria é marcada por um infindável tornar-se-outro, por exemplo, uma determinada árvore irá repor sempre o conteúdo genético de sua espécie: enquanto mangueira, mangas; goiabeira, goiabas; o tigre produzirá tigres e assim tem sido a perpertuação dessas esferas.

Conforme a explicitação das categorias ontológicas, o ser social devidamente constituído se deu a partir do fundamento do trabalho. Logo, o trabalho torna-se protoforma de toda práxis social, sua forma originária na distinção desse ser em relação às outras espécies existentes. Para tanto, Engels compreendeu que é pelo trabalho que o homem atingiu o processo de humanização. Investigou os antecedentes biológicos que o trabalho desenvolveu a partir do "salto" do animal ao homem e que se comprova na função diferente que a mão já exerce na vida do macaco:

O número e a disposição geral dos ossos e dos músculos são os mesmos no macaco e no homem, mas a mão do humano selvagem mais primitivo é capaz de executar centenas de operações que não podem ser realizadas pela mão de nenhum 
macaco. Nenhuma mão simiesca construiu jamais um machado de pedra, por mais tosco que fosse ${ }^{2}$.

Com efeito, ao estudar o desenvolvimento do homem (desde sua origem, mas partindo da sociedade capitalista), Marx descobre o intrincado que envolve as relações sociais numa situação historicamente posta e suas contradições do sistema capitalista moderno. Portanto, ao destacar a importância da centralidade ontológica do trabalho, pelo qual o possibilitou elucidar como os homens produzem todas as relações e complexos sociais, principalmente a sua essência, que não é uma dádiva divina ou natural; nem é algo que preceda a existência do homem. Ao contrário, a essência humana é produzida pelos próprios homens, dito de outro modo: o que o homem é, compõe-se pela sua atividade produtiva, que é o trabalho. Evidenciando que a realidade histórica e material é produzida pelo conjunto dos homens sob determinadas condições.

Entretanto, Marx destaca que o trabalho sob a sociabilidade capitalista moderna, assume uma forma particular, o trabalho abstrato, cuja base é a propriedade privada dos meios de produção. Suas observações recaem no desenvolvimento das forças produtivas materiais e humanas na indústria, já por volta do século XIX, no qual a riqueza acumulada proporcionava satisfação para alguns; e a miséria para outros. Esse fato demonstra que a camada miserável da população que exercia a atividade produtora, e que tanto trabalhava quanto vivia de forma degradante e desumana. Nesse contexto, destacamos que "o processo de objetivação traz consigo o momento do estranhamento, onde a objetivação surge como 'perda do objeto', a atividade produtiva torna-se atividade que desrealiza o homem" (Chagas, 1994, p. 28).

É por isso que, na atividade produtiva, a condição do trabalhador no sistema capitalista é a de mercadoria e sua condição torna-se pior à medida que a riqueza cresce. O caráter desumanizante que o trabalho assume, força

\footnotetext{
${ }^{2}$ ENGELS, Friederich. O Papel do Trabalho na Transformação do Macaco em Homem de 1876. Transcrição de cedida por "O Vermelho" para Marxists Internet Archive. 2004 HTML por José Braz para Marxists Internet Archive. 2004 p.2.
} 
o trabalhador a um tipo de sacrifício, isto é, efetivar sua práxis produtiva apenas pela troca da manutenção de sua existência e de seus filhos. Marx (2006, p. 828) nos esclarece que:

O processo que cria o sistema capitalista consiste apenas no processo que retira ao trabalhador a propriedade de seus meios de trabalho, um processo que transforma em capital os meios sociais de subsistência e os de produção e converte em assalariados os produtores diretos.

Nesse sentido, o capital, desde o seu nascimento, utilizou-se da ação violenta para consolidar-se enquanto modo generalizado de produção de mercadorias - produtor de mais-valia extraída da força de trabalho viva e assalariada, expropriada pela propriedade privada, na sua fase mais perversa e aniquiladora do seu metabolismo "oniabrangente" sob forma nunca antes vista. Ao consolidar-se como um sistema ampliado de reprodução, o capital subordina hierarquicamente, através de mecanismos estruturantes, todo o processo de trabalho, direcionando toda a produção à lógica da acumulação, às leis do mercado. Portanto, a forma histórica da produção é também a forma da sua reprodução, isto é, tem como característica particular o processo de acumulação de capital. Sem levarmos em conta esse aspecto, não compreenderíamos que, sem acumulação de capital, o sistema não perduraria.

Com efeito, sob as relações sociais burguesas, o trabalho é fetichizado, assalariado e sua única finalidade é produzir a partir de padrões determinados mercadorias para o consumo imediato num processo contínuo de acumulação privada.

Nessa lógica, a sociabilidade desenvolvida sob o processo de acumulação privado se apresenta dotada de características próprias, diferenciada de suas outras formas sociais que a precederam, por exemplo, a sociedade antiga, a sociedade feudal. Todavia, a sociedade burguesa destacou-se por apresentar todos os elementos que possibilitariam o nascimento de outra ordem, denominada de sociedade capitalista burguesa. 
Para tanto, somente nos últimos séculos, sob a forma burguesa capitalista, o capital atingiu com êxito sua forma estruturante de um “sistema orgânico”. De acordo com Marx, as relações que se estabelecem pelo capital surgem de outras formas tradicionais. Assim,

É preciso ter em mente que as novas forças de produção e as novas relações de produção não se desenvolvem a partir do nada, nem caem do céu, nem nascem tampouco do útero da Ideia que a si mesma se põe; mas se formam no interior e em antítese ao desenvolvimento da produção existente e às relações de propriedade tradicionais herdadas. Se em pleno sistema burguês cada relação econômica pressupõe todas as outras em sua forma econômica burguesa, e tudo o que foi posto é, portanto, também um pressuposto, então o mesmo se dá com qualquer sistema orgânico. Esse mesmo sistema orgânico, como totalidade, tem seus pressupostos, e seu desenvolvimento em direção à totalidade consiste precisamente em subordinar a si todos os elementos da sociedade, ou criar a partir dela os órgãos de que ainda carece; eis como historicamente ele se torna uma totalidade (Marx apud Mészáros, 2007, p. 55-56).

Todavia, em nosso entendimento, evidenciamos que o poder metabólico do capital e sua tendência ao expansionismo - e com ele a degradação da humanidade - não constitui um defeito, mas é sua característica fundamental - de ser incontrolável e irreformável - nessa sociabilidade. Para tanto, o século XX acompanhou diversas tentativas direcionadas à superação das limitações sistêmicas do capital, que a história demonstrou como grandes equívocos. Sendo assim, desde o keynesianismo estatal ao modelo econômico soviético, que na realidade comprovaram incapacidade no intuito de garantir a estabilidade permanente em seu processo de reprodução. Essas tentativas de controle só serviram para uma forma que Mészáros denominou de "hibridização" do sistema do capital. Na verdade, tais amarras apenas retardaram seu metabolismo por algum tempo, mas logo surgiram oportunidades que as romperam e o capital pode continuar expandindo-se já por quase todo o planeta. Para tanto, Mészáros (Ibidem, p. 56) nos informa que

libertando seus antiquíssimos componentes orgânicos das algemas dos sistemas orgânicos anteriores e demolindo as barreiras que impediam o desenvolvimento de novos 
componentes vitais, o capital como um sistema orgânico oniabrangente pôde afirmar sua vigência nos últimos três séculos como produção generalizada de mercadorias. Reduzindo e degradando os seres humanos à condição de meros "custos de produção" como "força de trabalho necessária", o capital pôde tratar até mesmo o trabalho vivo como nada mais que "mercadoria comercializável", igual a qualquer outra, sujeitando-o às determinações desumanizadoras da coerção econômica.

Assim sendo, a sobrevivência da humanidade e, por sua vez, do planeta dependerá de quais alternativas de escolha teremos: a perspectiva de reforma do sistema do capital e suas múltiplas fetichizações de caráter mercadológico ou a erradicação da forma de ser desta sociabilidade em direção a um novo modo de produção organizado pelos próprios produtores associados, onde as condições de existência sejam verdadeiramente humanas, voltadas para a satisfação das necessidades materiais e espirituais de todo o conjunto da humanidade.

Com efeito, para nossa melhor compreensão, expomos os nexos que circunscrevem nosso texto que trata do Projeto de Educação para Todos com foco na escolarização básica. Para tal intento são determinadas quais aprendizagens passam a ser definidas nos programas de formação para a classe trabalhadora e que se encontram descritas nos documentos de Jomtien (1990) e o Marco de Dacar (2000) difundidas pelos programas de Educação para Todos. Para tanto, é proposta uma ampla reestruturação dos sistemas nacionais de ensino, destacando as aprendizagens necessárias em nível restritivo, minimalista e fragmentado - objetivo esse a ser alcançado pelos países da periferia do capital.

Por sua vez, antes de adentrarmos a temática sugerida acima, destacamos importante o entendimento de que trabalho e educação são atividades exclusivamente humanas. Tonet (2007), a partir de Marx, nos apresenta uma distinção bastante significativa entre o aspecto ontológico do trabalho e as outras esferas, devidamente entendido aqui o complexo da educação. Para tanto, “entendemos que o trabalho é o fundamento ontológico do ser social. E que todas as outras dimensões sociais - a 
exemplo da política, do direito, da ciência, da arte, etc - mantêm com ele uma relação de dependência ontológica e de autonomia relativa” (p. 27). Assim sendo, para Lukács (1979, p. 87), a dependência ontológica tem sua base no aspecto onde,

[...] o trabalho é, antes de mais nada, em termos genéticos, o ponto de partida da humanização do homem, do refinamento das suas faculdades, processo do qual não se deve esquecer 0 domínio sobre si mesmo. Além do mais, o trabalho se apresenta, por um longo tempo, como o único âmbito desse desenvolvimento; todas as demais formas de atividade do homem, ligadas aos diversos valores, só se podem apresentar como autônomas depois que o trabalho atinge um nível relativamente elevado.

No trabalho, momento predominante, a educação constitui uma mediação. Dessa forma, permiti-nos averiguar que, as apropriações resultantes do conjunto da riqueza elaboradas historicamente e que são transmitidas no contexto da práxis, em Lukács (2009, p. 115), esse momento é denominado de "segunda natureza”, onde tal processo é originado a partir de posições teleológicas secundárias, isto é, da relação homem a homem, por sua vez mediatizada pela educação.

Que tal processo seja social, que não se trate de um simples crescimento biológico, podemos vê-lo já no fato de que também ele consiste em uma cadeia, em uma continuidade dinâmica de decisões alternativas. E sob um duplo aspecto: por um lado a educação do homem é dirigida para formar nele uma disponibilidade em relação às decisões alternativas de um determinado gênero; onde a educação não é entendida em sentido estrito, como atividade consciente, mas como totalidade das influências exercidas sobre o novo homem em formação.

Nesse sentido, a educação foi fundada pelo trabalho como uma práxis, cuja essência pudesse mediatizar o sistema de relações entre os próprios homens, que interviesse nas suas consciências numa perspectiva de agirem desse ou daquele modo, isto é, que garantisse o processo de reprodução do patrimônio histórico às gerações mais jovens. Logo, tal práxis tem sua gênese a partir do período em que o homem se elevou à condição de ser social. 
Em breve trajetória histórica, o Projeto de Educação para Todos apresenta sua gênese a partir da ascensão da burguesia ao poder, em que determinou novas relações sociais e um novo modo de produção, em substituição a sociedade feudal. É nesse momento que se cogita a importância de um tipo de escolarização necessária que viesse atender à classe trabalhadora in status nascendi, de modo a que esta se adequasse às necessidades postas pelo advento do capitalismo. Sob a hegemonia do Estado, ergue-se a bandeira de uma escola pública, universal, gratuita para todos e laica. Sobre a temática, Tonet (2005, p. 221), esclarece:

Até o advento do capitalismo o acesso a esta esfera - mesmo assim de modo bastante diferenciado - era restrito às classes dominantes. Isso se justifica porque as qualificações necessárias àqueles que dirigiriam a sociedade e deteriam o controle do acesso aos bens materiais e espirituais não seriam necessários àqueles cuja única tarefa era o trabalho. Para estes continuava sendo suficiente a educação para o trabalho. [...] com o advento do capitalismo [...] a educação passou a ocupar um lugar todo especial, porque passou a integrar cada vez mais profundamente o processo de produção.

Por conseguinte, está posto que a escola tem um amplo papel na reprodução do modo de produção capitalista. Visto que, se por um lado, ela foi apartada do processo de produção no escravismo e no feudalismo, por outro, será vital no capitalismo pelo processo de formação das consciências, mas assumirá um refinamento pautado pela categoria da cidadania, resguardada sob o princípio da igualdade formal. Ademais, apostando que todos são livres e iguais, conforme proclama a Declaração dos Direitos do Homem e do Cidadão (1789). De acordo com essa declaração, Art. 1. "Os homens nascem e são livres e iguais em direitos. As distinções sociais só podem fundamentar-se na utilidade comum”. Assim sendo, a respeito dessa proclamada igualdade entre os homens, Tonet ( 2007, p. 76) esclarece

A sociedade capitalista também é uma sociedade de classes. Porém, entre ela e as formas anteriores - asiática, escravista, feudal e outras - há uma diferença importante. É que nas formas anteriores a desigualdade era tida como algo natural. Por isso mesmo, a exclusão das classes subalternas do acesso à riqueza também era vista como algo absolutamente natural. Ao contrário, na sociedade burguesa é proclamada a igualdade de 
todos os homens por natureza. O que significa que, em princípio, todos eles deveriam poder ter acesso ao conjunto do patrimônio humano. No entanto, como isso, de fato, não é possível (justifica-se essa impossibilidade pela desigualdade que resultaria da livre iniciativa, expressão do inato egoísmo humano), a dissociação entre discurso e realidade efetiva impõe-se como uma necessidade. Proclama-se o direito de todos a uma formação integral. Mas, de um lado, a maioria é excluída do acesso aos meios que possibilitariam essa formação e, de outro, essa mesma formação é definida privilegiando os aspectos espirituais: formação moral, artística, cultural, intelectual.

Com efeito, como as novas relações de produção econômica passaram a ser assalariadas, o motor da própria dinâmica do capital, de acordo com Tonet (2005) as classes trabalhadoras não poderiam receber educação pela prática do trabalho, tendo em vista a complexificação dos processos de trabalho que se consolidava. Nesse contexto, a Educação na intensificação da divisão do trabalho assume uma dimensão específica e que se exige do trabalhador conhecimentos e habilidades mais complexos, que teria que ser buscado fora do âmbito do trabalho.

Sendo assim, o marco dessa nova configuração do trabalho ocorreu na Revolução Industrial, com a expansão das forças produtivas e de toda sorte de invenções que implementaram o processo produtivo tem sua gênese na Inglaterra. Assim, com o aparecimento das máquinas, ocorre uma profunda alteração do processo produtivo das fábricas como também nas relações de produção, no estilo de vida das pessoas, das ideias, nos costumes e, consequentemente, na própria instrução.

Consequentemente, a Educação no modo de produção capitalista terá influências das revoluções da América e da França, que promulgavam em suas declarações à necessidade de haver uma escolarização universal e de organização do saber, efetivamente articulado com a indústria moderna e com a própria ciência.

Nesses termos, o papel da educação, a exemplo de políticas reformadoras do iluminismo, enumerando os governos de Franklin (17061790) e Jefferson (1743-1826), defensores dos princípios do direito natural e 
da racionalidade do homem e nas concepções locksianas, propõem na fundação da nova Confederação dos Estados Independentes, uma proposta de uma educação destinada a todos, amparadas no aprendizado de línguas e nos fundamentos das ciências modernas. Na íntegra, o grande marco referente aos direitos sociais está objetivado no Projeto Americano.

Nesse programa, detectamos um processo seletivo, onde a escola proposta por Jefferson estendia sua gratuidade para todas as crianças dos sete aos dez anos, sendo que alguns que se destacassem poderiam frequentar a escola secundária e que outros iriam para universidade. Observamos que, no interior desse projeto, já encontramos, de forma embrionária, elementos característicos da pedagogia liberal-democrática, que se articulava amplamente com o processo da universalização da instrução formal pautada nos marcos da ideologia burguesa.

De forma semelhante, encontramos na França Revolucionária após 1789 praticamente os mesmos objetivos do projeto estadunidense, diferenciados apenas em aspectos culturais, cujos princípios interlocutores mais importantes, destaca-se Rousseau (1712-1778). Consequentemente, na Constituinte Francesa que surgiu a partir dos Estados Gerais, foi proposta a Declaração dos Direitos do Homem e do Cidadão conforme já mencionamos no presente texto. Nela, comprovamos que

A ignorância, o esquecimento ou o desprezo dos direitos do homem são as únicas causas dos males públicos e da corrupção dos Governos [...] Art.1 ${ }^{\circ}$. Os homens nascem e são livres e iguais em direitos. As distinções sociais só podem fundamentarse na utilidade comum. Art. $2^{\circ}$. A finalidade de toda associação política é a conservação dos direitos naturais e imprescritíveis do homem. Esses direitos são a liberdade, a propriedade, a segurança e a resistência à opressão. [...] Art.5 . A lei não proíbe senão as ações nocivas à sociedade. Tudo que não ordene. Art. $6^{\circ}$. A lei é a expressão da vontade geral. Todos os cidadãos têm o direito de concorrer, pessoalmente ou através de mandatários, para a sua formação. Ela deve ser a mesma para todos, seja para proteger, seja para punir. Todos os cidadãos são iguais a seus olhos e igualmente admissíveis a todas as dignidades, lugares e empregos públicos, segundo a sua 
capacidade e sem outra distinção que não seja a das virtudes e a dos seus talentos ${ }^{3}$.

Para tanto, entendemos que a proposta de universalização da educação encontra seus fundamentos na Declaração dos Direitos do Homem e do Cidadão, pós-França Revolucionária, onde temos a consolidação desses ideais a partir de Condorcet, protagonista mais significativo dessa nova fase da França, que na ocasião secretário da Assembleia Legislativa, defende o seu Rapport sur l'instruction publique, demonstrando a necessidade de escolarizar, instruir todo o povo, cabendo ao Estado o dever de assumir essa educação gratuita. Desse modo, Manacorda (2006, p. 250-251) aborda suas afirmativas:

A Constituição não pode permitir na instrução pública um ensinamento que, afastando os filhos de uma parte dos cidadãos, destruiria a igualdade das vantagens sociais [...]. É [...] rigorosamente necessário separar da moral os princípios de qualquer religião particular e não admitir na instrução pública o ensinamento de algum culto religioso. Este deve ser ensinado nos templos pelos seus ministros.

Com o acentuado avanço da produção capitalista, com a implementação das máquinas e necessária expansão comercial e demanda por mão de obra, incorporando homens, mulheres e crianças nas atividades intensamente exploradas pelo capital, Condorcet levanta nesse contexto, a bandeira da gratuidade das escolas, o que não resultaria em acesso da classe trabalhadora, haja vista que o trabalho infantil por ser muito lucrativo na expansão do capitalismo, não poderia ser extinto. Assim sendo, podemos ilustrar a realidade das crianças no processo de trabalho nos primórdios da implementação da indústria na poesia chamada Melancolia de Victor Hugo:

Aonde vão essas crianças entristecidas? Tão frágeis e tão sérias, tão emagrecidas? Meninas de oito anos sozinhas andando? Quinze horas na máquina estarão trabalhando; da manhã à noite, sem parar um momento, farão na mesma prisão o mesmo movimento sob os dentes de uma máquina ferina, qual monstro hediondo que no escuro rumina.

\footnotetext{
3 Declaração dos Direitos do Homem e do Cidadão. Disponível em: $<$ http://educaterra.terra.com.br/voltaire/mundo/declaracao.htm>. Acesso em: 28.2.2008.
} 
No entanto, as experiências de instrução levadas a cabo por Joseph Lancaster (1778-1838), expressavam a firme adesão ao processo da divisão social do trabalho, pois a indústria na fase de manufatura necessitava da adaptação dos trabalhadores ao trabalho parcelar (por partes). Logo, no que tange à defesa da extensão da escolarização a todos, desde já seus teóricos demonstravam grande preocupação com os custos, de modo que um programa monitorial atenderia perfeitamente à consolidação de uma educação pública de características universais, cujos conteúdos "ler, escrever, fazer contas são necessidades de todos e são também os únicos conhecimentos, que é possível dar mediante uma instrução direta e positiva aos habitantes das cidades e dos campos” (Manacorda, 2006, p. 252).

Todavia, a sociedade burguesa nascente, para atingir o ápice dos seus objetivos, precisou arrancar todos os vestígios do feudalismo a fim de poder incorporar seu grande projeto liberal. Nesse sentido para atender aos interesses do capital, postulada numa sociedade livre para comercializar, se proclamava a liberdade do cidadão como um direito assegurado, embora tratasse de um tipo de liberdade restritiva, pois em seguida vinha o direito à propriedade privada. Grosso modo, essa sociabilidade se constituía por ser um avanço em relação ao modo de produção feudal. Para isso, a educação formal e universal era necessária para promover as disposições exigidas pela classe emergente: à formação do novo homem apto a adequar-se a uma nova sociedade em pleno processo de gestação, cujas relações sociais não poderiam mais trazer os antigos princípios e valores feudais a ordem vigente.

$\mathrm{Na}$ íntegra, o que estava por vir era o processo árduo e doloroso do modo de produção capitalista burguês, cuja característica fundante é a compra e venda da força de trabalho. Posto que, a consolidação da propriedade privada com fins à lucratividade determinou a exploração do trabalho alheio com vistas à acumulação do capital, transformando o dito trabalhador livre em assalariado, expropriado de suas ferramentas de trabalho e de seu pedaço de terra, restando-lhe apenas um par de braços para continuar vivendo. Marx nos informa ainda que 
a burguesia é considerada como uma classe revolucionária veículo da grande indústria - diante dos senhores feudais e das camadas médias, empenhados, aqueles e estas, em manter posições sociais que foram criadas por formas caducas de produção"4.

Na realidade, o capital, para se afirmar como um único modo de produção vigente foi capaz de aniquilar populações inteiras no intuito de transformar o então trabalhador livre numa condição de assalariamento, cuja forma negociável se dá pela disposição do trabalhador em vender sua força de trabalho no mercado, como uma mercadoria qualquer como também já estava explícito que se deveriam formar homens com conteúdos de classes distintos para uma sociedade de classes onde o capital é o único a usufruir do manto da liberdade, livre para explorar e acumular. Maceno (2005, p. 64) afirma:

\begin{abstract}
Ora, o modo de produção capitalista colocava o homem no centro do mundo, apresentava um projeto superior de realização humana, onde o homem era "livre" e pleno de direitos e defendia um regime de governo que exigia a participação dos "cidadãos”. Esse homem, em que pese ser dividido em classes, precisava de outros tipos de educação, com novos conteúdos e métodos e com novas diferenciações. Nesse sentido, o homem da classe trabalhadora precisava ter acesso a noções de primeiras letras e de civilidade. [...] a determinação que promove a perspectiva da universalização da educação só pode ser encontrada no trabalho.
\end{abstract}

Por conseguinte, compreendemos que o projeto de uma educação universalizante para todos nasce no momento da consolidação do sistema capitalista, conforme já mencionado por Tonet, onde o capital passa a gerir todas as formas de reprodução sociais voltadas unicamente para a acumulação de capital. A educação, por sua vez, passa a ser pensada numa perspectiva de implementar o processo produtivo, uma vez que o desenvolvimento da indústria requeria trabalhadores aptos ao manejo das ferramentas que ali se encontravam. De outro modo, não era mais possível o trabalhador receber formação no e pelo trabalho, principalmente com a rapidez em que o trabalho vinha se complexificando e exigindo cada vez

\footnotetext{
${ }^{4}$ MARX, K. Crítica ao Programa de Gotha.
} 
mais habilidades para efetivá-lo. O outro aspecto da educação consistia em desenvolver as disposições necessárias para uma sociedade liberaldemocrática, pois aqui caberia a inculcação das formas de ser, de agir e de pensar, às quais todos os ditos “cidadãos” deveriam corresponder.

Sendo assim, ao intentarmos uma análise acerca da ontogênese do Projeto de Educação para Todos, identificamos a educação como um complexo social fundado pelos próprios homens, mas que, nas últimas décadas do século XX tem constituído prioridade na agenda de entidades governamentais, setores da sociedade civil e dos organismos internacionais, na perspectiva de adequá-la a um programa de desenvolvimento econômico para os países periféricos.

Fato esse que se caracteriza pela fase de decadência do capitalismo no final do século XX. Vale lembrar que finda a Segunda Guerra Mundial e os Estados Unidos saem hegemônicos e passam a reorganizar o mundo capitalista e atuam significativamente no processo de reconstrução da Europa. Essa fase é tida como os anos áureos vividos pelo capital e que favoreceu o acúmulo de grandes capitais. Todavia, já por volta da década de 70 começa a cair à taxa de lucro e inicia a fase da crise estrutural do capital, detalhada por Mészáros (2003) como uma crise rastejante sem precedentes.

Ademais, essa crise tem seus rebatimentos na educação, onde os principais teóricos contemporâneos atribuem à educação o papel determinante na solução dos principais problemas que afligem a humanidade - como efetivar o combate à pobreza ${ }^{5}$; erradicar o desemprego, através da ideologia da empregabilidade e do empreendedorismo; desenvolver uma consciência de co-partícipe da mãe natureza tomando como referência a eco-sustentabilidade; estabelecer boas relações sociais, a partir do pilar "aprender a conviver" e, com isso, reduzir o nível da violência das comunidades; elaborar políticas de inclusão social, envolvendo a questão das “diferenças” entre as pessoas quer de natureza

\footnotetext{
${ }^{5}$ Sobre essa temática ver: JIMENEZ, S. V.; MENDES, S. M. das D. Erradicar a pobreza e reproduzir o capital: notas críticas sobre as diretrizes para a educação do milênio. Cadernos de Educação [FaE/PPGE/UFPel] Pelotas [28]: 119 - 137, janeiro/junho 2007.
} 
física, psicológica, sexual, etnia, gênero, daí a temática “diversidade” desde que não seja demonstrado o conteúdo da luta de classe, das relações antagônicas entre capital e trabalho, da exploração de uma classe parasitária sobre a classe trabalhadora, no sentido de reconduzir os novos processos de produção e reestruturação do capital em tempos de crise. Conforme Freres (2008, p. 51),

[...] trabalho e capital são radicalmente opostos, mas este não sobrevive sem a exploração do primeiro, subordinando-o à sua lógica. Nesse processo de subordinação do trabalho ao capital, este busca atrelar a si próprio as outras formas de práxis humana, dentre elas a educação [...]. Assim, educação e trabalho são as duas bases do desenvolvimento econômico e social dos países periféricos, sendo a primeira a categoria central no debate econômico das últimas décadas - estando a primeira na esfera do discurso.

Com efeito, a organização de um amplo programa de educação com foco no atendimento às necessidades básicas de aprendizagem dos países membros da UNESCO, constitui o objetivo basilar no campo das reformas, cujo horizonte está em promover a inserção do trabalhador nas diferentes modalidades e atividades informais para um mercado em constante mutação.

Partimos das análises de documentos oriundos de conferências nacionais e internacionais que referendaram declarações de Educação para Todos. A primeira, denominada Conferência de Jomtien (1990) é considerada importante pela sua abrangência na reorganização dos processos educativos em âmbito mundial. Caracterizou-se por seu fundamento estratégico ao conferir um programa de reformas que a educação deveria ajustar-se, de modo a atingir os objetivos de sustentabilidade, equidade ${ }^{6}$ e de combate à pobreza para o desenvolvimento dos países pobres, com ênfase na universalização da educação básica.

\footnotetext{
${ }^{6}$ Não significa o mesmo que igualdade, "considerado teoricamente, o termo equidade vem do Direito e, mais precisamente, da prática jurídica. Nesse campo, a equidade fundamentase numa justiça mais espontânea e corretiva, não se restringindo à letra da lei, podendo mesmo contrariá-la em respeito às circunstâncias e à natureza intrínseca do objeto jurídico considerado. Esta acepção tem base na reflexão aristotélica segundo a qual a natureza da equidade é a retificação da lei quando esta se mostra imperfeita, por seu caráter universal, para casos particulares” (Fonseca, 1998, p. 6).
} 
Assim, de acordo com Mendes Segundo (2006, p. 229), sob o patrocínio do Banco Mundial, a conferência de Jomtien teve,

[...] como acordo, nos países-membros, o compromisso da universalização da educação básica para a população mundial, fundamentada no entendimento em que este nível é satisfatório às necessidades de aprendizagem. Para alcançar esse objetivo, todos os participantes deveriam adaptar, em seus países, estratégias com vistas a assegurar o direito a uma educação básica de qualidade, com impactos na sociedade e na vida das pessoas.

Sob o patrocínio do Banco Mundial, órgão fomentador das principais estratégias políticas educacionais, articulado junto a Organização das Nações Unidas para Educação, Ciência e a Cultura (UNESCO), o Fundo das Nações Unidas (UNICEF) e o Programa das Nações Unidas para o Desenvolvimento (PNUD), corroboram as mais diferentes ações através de inúmeros projetos sócioeducativos, no alinhamento dos países pobres a nova ordem neoliberal do capital.

Com efeito, Jimenez (2005), na esteira de Leher (2001), demonstra que o sistema do capital elaborou um projeto de metas através do qual sustenta tanto ações voltadas para a estabilidade financeira e ajustes estruturais quanto para a viabilização de um receituário ideológico. Nesse sentido, o Banco Mundial personifica o organismo central dessas deliberações, onde, particularmente, é dedicado um espaço à educação nos seus documentos e receituários. Nesse sentido, conforme Jimenez,

[...] como o "Ministério Mundial da Educação" - um exame mais criterioso indica que a preocupação principal que move as ações daquele Banco não se referem propriamente ao desenvolvimento da educação dos países periféricos, mas antes e, sobretudo, à estabilidade política, a ser garantida por um sistema educacional capaz de produzir as adequadas “disposições ideológicas” nos trabalhadores, diante das severas condições do mercado de trabalho (p. 3).

Sob tal perspectiva, o papel da educação como estratégia de redução das desigualdades sociais nos países pobres da periferia do capital foi posto a partir da década de 70, período em que a questão da pobreza já ocupava prioridade na política do Banco. Para os burocratas, o problema dependia 
menos do crescimento do país e mais do aumento da produtividade dos pobres. Ademais, o então presidente do Banco McNamara (gestão marcada pela preocupação específica com a pobreza) apresentou os princípios que deveriam orientar os sistemas educacionais dos países em desenvolvimento. Segundo seu pronunciamento "todo ser humano deve receber um mínimo de educação básica na medida em que os recursos financeiros o permitam e as prioridades do desenvolvimento o exija” (Fonseca, 1998, p. 7).

Dessa forma, todos esses países acordaram na integra o compromisso de implantar e executar as seis grandes metas $^{7}$ do Programa Mundial de Educação para todos aprovadas na Declaração Mundial sobre Educação para Todos e o Esquema de Ação para Satisfazer as Necessidades Básicas de Aprendizagem. Nesse contexto, a universalização do ensino elege como categoria central a necessidade de satisfazer a aprendizagem básica nos países pobres. A nosso ver, as condições básicas postuladas nos declarações de EPT são compreendidas como mínimas, em que define a aprendizagem básica como sendo aquela pautada em “conhecimentos úteis” que os indivíduos precisam aprender para atender as necessidades do capital. Por conseguinte, no artigo $1^{\circ}$, presente na referida declaração, por necessidades básicas de aprendizagem, o texto denota que,

[...] tanto os instrumentos essenciais para a aprendizagem (como a leitura e a escrita, a expressão oral, o cálculo, a solução de problemas), quanto os conteúdos básicos da aprendizagem (como conhecimentos, habilidades, valores e atitudes), necessários para que os seres humanos possam sobreviver, desenvolver plenamente suas potencialidades, viver e trabalhar com dignidade, participar plenamente do desenvolvimento, melhorar a qualidade de vida, tomar decisões fundamentais e continuar aprendendo (p. 3).

\footnotetext{
${ }^{7}$ Conferência Mundial de Educação Para Todos. Jomtien, Tailândia, 1990. Disponível em: <www.unesco.br.> Acesso em: 13 set. 2004. (1. A expansão dos cuidados e atividades, visando ao desenvolvimento das crianças em idade pré-escolar; 2 . O acesso universal ao ensino fundamental (ou ao nível considerado básico), que deveria ser completado com êxito por todos; 3. A melhoria da aprendizagem, tal que uma determinada porcentagem de um grupo de faixa etária "x" atingisse ou ultrapassassem o nível de aprendizagem desejado; 4. A redução do analfabetismo adulto à metade do nível de 1990, diminuindo a disparidade entre as taxas de analfabetismo de homens e de mulheres; 5 . A expansão de oportunidades de aprendizagem para adultos e jovens, com impacto na saúde, no emprego e na produtividade; 6 . A construção, por indivíduos e famílias, de conhecimentos, habilidades e valores necessários para uma vida melhor e um desenvolvimento sustentável).
} 
Nessa perspectiva, a Declaração de Jomtien (1990) entende que pode superar o fosso do analfabetismo ainda existente no mundo, atribuindo ao Programa de Educação para Todos, sobretudo, a educação básica como a política capaz, não somente de promover um mundo mais seguro, sadio, tolerante, próspero e economicamente autônomo, mas apta a oferecer à sociedade condições de respeitar o ambiente, as diversidades, conviver em paz e aprofundar a solidariedade entre os povos. Para tanto, proclama a cooperação e o envolvimento de toda a sociedade civil ${ }^{8}$.

Com efeito, o projeto de Educação para Todos, sob a tutela do Banco Mundial, inspirada ideologicamente por uma estratégia política e de cunho econômico, disponibiliza programas que trazem na íntegra um caráter compensatório, com predomínio da racionalização de recursos, da equidade - não da igualdade substantiva - (Mészáros, 2003) e do gerenciamento eficaz para os países periféricos. Nesse sentido, a tentativa de promover o sonhado desenvolvimento econômico e a redução da pobreza ancorada, portanto, como não é possível negar, com as necessidades de reprodução do capital em sua lógica sócio-metabólica, vem solapando todas as dimensões sociais de forma destrutiva. Sendo assim, Mészáros (2007, p. 58) afirma que “é a expansão do capital como um fim em si mesmo, servindo à preservação de um sistema que não poderia sobreviver sem afirmar constantemente seu poder como um modo ampliado de reprodução”. Dessa forma, avança em disseminar estratégias mistificadoras da realidade e continuar seu processo metabólico de reprodução social.

Na verdade, os projetos educacionais têm como horizonte adaptar-se aos ditames do então mundo globalizado (ou, ainda, da sociedade do conhecimento), de modo a ajustar um conjunto de reformas introduzidas na educação, em todos os níveis e modalidades. No caso brasileiro, a expressão mais contundente se deu com a promulgação da Lei de Diretrizes e Bases da

\footnotetext{
${ }^{8}$ É composto por uma gama de colaboradores como famílias, professores, comunidades, empresas privadas (inclusive as da área de informação e comunicação), organizações governamentais e não-governamentais, instituições, etc. Todos são convocados para participarem ativamente na planificação, gestão e avaliação das inúmeras formas assumidas pela educação básica (Unesco, 1990, p. 11).
} 
Educação (LDB nº. 9.394/96) cujo conteúdo do texto afina-se com as orientações da Declaração de Jomtien.

Nesse sentido, na concretização desses interesses, são impostas mudanças de ajustes no sentido de reestruturar as instituições de educação sob a orientação do Banco Mundial. A partir de um caráter de compromissos, é acordado o monitoramento das políticas a serem implementadas pelo país tomador de empréstimos no intuito de manter a governabilidade. Para tanto,

[...] impõem-se mudanças devastadoras, aplicando-se aos padrões de financiamento e à forma de gestão dos sistemas de ensino, como às definições curriculares, aos processos avaliativos e modelos de formação docente, critérios estritamente empresariais e mercadológicos [...] a contenção dos gastos com a educação pública, priorizando, mesmo assim avaramente, o ensino fundamental, lançando o ensino médio e o superior à arena da privatização, além de fazer jorrar suas graças financeiras pelos cofres das empresas privadas de ensino superior [...] formas camufladas ou não tanto, de negação do conhecimento, como o ensino a distância, a fragmentação dos currículos, a redução do tempo de duração dos cursos, ou o treinamento docente em serviço, além da implementação da pedagogia das competências, ou, de um modo mais genérico, do aprender a aprender, o Banco conta que a educação promova, sob sua tutela, a inserção dos países pobres no mapa da globalização, além de garantir que todas as pessoas obtenham conhecimento necessário a uma vida melhor e a um desenvolvimento sustentável (Jimenez \& Mendes Segundo, 2007, p. 124-125).

Na mesma direção de cumprir a meta primordial de universalização primária, o Marco de ação de Dacar, em 2000, avaliou essa década de Jomtien e não apenas reiterou as principais metas $^{9}$ como inovou em outras.

\footnotetext{
9 I. Ampliar e aperfeiçoar os cuidados e a educação oferecidos à primeira infância, principalmente para as crianças mais vulneráveis e carentes; II. Assegurar que, até 2015, todas as crianças em "situação difícil”, principalmente as meninas, e as que pertencem a minorias étnicas ao acesso e permanência à educação primária obrigatória de boa qualidade; III. Assegurar as necessidades educacionais de todos os jovens e adultos, por meio do acesso equitativo a bons programas de ensino e de aquisição de habilidades de vida; IV. Alcançar, até 2015, uma melhoria de 50\% nos níveis de alfabetização de adultos, especialmente para mulheres, bem como o acesso equitativo à educação básica e contínua para todos os adultos; V. Eliminar, até 2005, as disparidades entre os gêneros no ensino primário e secundário e alcançar qualidade na educação de ambos os gêneros até 2015; VI. Aperfeiçoar a qualidade da educação e assegurar excelência para todos, de modo que os resultados acadêmicos reconhecidos e mensuráveis sejam alcançados por todos,
} 
No intuito de manter o Plano de Aprendizagem como o instrumento necessário à superação das desigualdades diagnosticadas, o Marco de Ação de Dacar reforçou a atuação dos chamados novos paradigmas da educação, definidos como "aprender a aprender, aprender a fazer, aprender a conviver, aprender a ser”. A grande novidade desse documento se refere à preocupação com relação à igualdade de gênero e à capacitação da mulher, como também com relação à diversidade e ao multiculturalismo para melhor convivência dos povos.

Afirmamos que a proposta de Educação para Todos está destinada a uma educação do e para o pobre, destacando, nesses termos, um baixo custo financeiro e uma “instrução” afinada com a formação do trabalhador de uma economia de mercado. Assim sendo, a educação promovida pelo Banco Mundial, cujo argumento é suprir as carências mais críticas da educação nos países da periferia do capital, impõe-se como prioridade, estabelecendo programas para o ensino fundamental direcionados a responder às necessidade básicas de aprendizagens das crianças em idade escolar, especialmente das mulheres e adultos analfabetos.

\section{Considerações finais}

Reiteramos assim, que o Programa de Educação para Todos surge, portanto, como instrumento de concessões utilizado pelos países ricos no direcionamento de promover adesão de toda a sociedade para a superação da crise vivida pela sociedade capitalista, diagnosticada nas últimas décadas pelo decréscimo das taxas de lucro. De modo que, para minimizar possíveis conflitos entre as classes, fomentaram-se políticas compensatórias de alívio à pobreza, garantindo por todos os meios à reprodução da lógica do capital, cujo propósito é estimular as competências, a eficácia dos seus sistemas e a produtividade da força de trabalho.

principalmente em termos de alfabetização, conhecimentos aritméticos e habilidades importantes para a vida (Pronunciamento Latino-Americano Sobre "Educação para Todos" Por ocasião do Fórum Mundial da Educação (Dacar, 26-28 abril, 2000). 
Ademais, a proposta de aprendizagens é considerada restritiva e minimalista, compreendendo: a leitura e a escrita, a expressão oral, o cálculo, a solução de problemas e a "formação de hábitos e atitudes”. O programa de aprendizagem da EPT apresenta uma formação aligeirada, desdobrando em um ensino limitado a classe trabalhadora, confinando-a a ocupação de postos de trabalhos autônomos ou informais, sob uma lógica do lema do empreendedorismo.

Nesse sentido, o estudo detalhado acerca dos documentos de EPT aponta que o eixo temático concentra-se em alcançar a universalização da educação básica como satisfatória às necessidades de aprendizagem dos países populosos e pobres no enfretamento da pobreza, no ajuste e adaptação a lógica do capital em crise.

Apontamos que a categoria da universalização da educação foi assinalada no momento em que a burguesia assumiu o poder como classe emergente. No primeiro momento, a Declaração dos Direitos do Homem e do Cidadão advoga a formação para todos e em igual proporção. Em outro momento, defendeu sua universalização em doses homeopáticas, ou seja, as doses certas teriam como critério a classe social do indivíduo.

Ademais, até aqui, o termo "instrução" estava articulado a um tipo de educação universal, em que todos os indivíduos dela poderiam se beneficiar. Todavia, quando o processo de trabalho se encontra cada vez mais complexificado e voltado ao processo de acumulação do capital, a instrução terá a finalidade de atender às determinações do processo produtivo.

Assim, no decorrer da história, a instrução ou aprendizagem, sofreu modificações significativas ao longo dos pacotes educacionais desenvolvidos para atender às reformas governamentais atreladas ao sistema do capital. Nas últimas décadas do século XX, o golpe maior se deu com a Conferência de Educação para Todos (1990), propondo o esvaziamento do conhecimento, por aprendizagens mínimas e aligeiradas focadas no “aprender a aprender”, proposta de escolarização básica necessária aos pobres. 
Asseveramos que, sob esse prisma, a educação, antes atribuída à instrução, em que se compreendia como ensino, saber, apropriação do conhecimento, hoje se restringe a 'aprendizagens de conhecimentos úteis', habilidades, aptidões e valores que os trabalhadores desse século devem apropriar-se e que se ajustam aos interesses de acumulação ampliada do capital. Em suma, a ofensiva do capital tem imposto um discurso falseado ‘da Educação para Todos', mascarando a estratégia de manter a lógica perversa de exploração da classe trabalhadora e a sustentabilidade do sistema capitalista através de um amplo programa hegemônico de controle social, liderando os processos de reforma e ajustes nos países membros.

\section{Referências Bibliográficas}

BRASIL, Lei $n^{0}$ 9394, 20 de dezembro de 1996. Estabelece as Diretrizes da Educação Nacional. Brasília, 1996. Disponível em: <http://www.mec.gov.br/sef/fundef/lei 9394.pdf>. Acesso em 14. jan. 2004.

CHAGAS, E. Ferreira. Diferença entre Alienação e Estranhamento nos Manuscritos Econômico-Filosóficos (1844), de Karl Marx. In: Revista Educação e Filosofia. Uberlândia: Universidade Federal de Uberlândia, Junho/Dezembro de 1994, vol. 8, no 16, p. 28.

FONSECA, Marília. O Banco Mundial como referência para a justiça social no terceiro mundo: evidências do caso brasileiro. Rev. Fac. Educ. v. 24 no 1 São Paulo jan/jun. 1998.

FRERES, Helena de A. A educação e a ideologia da empregabilidade: formação para o (des) emprego. Dissertação (Mestrado) - Programa de Pós-Graduação em Educação Brasileira da UFC. Fortaleza, 2008, 141 p.

JIMENEZ, S. V. e MENDES SEGUNDO, M. das D. Erradicar a pobreza e reproduzir o capital: notas críticas sobre as diretrizes para a educaşão do novo milênio. Cadernos de Educação - Universidade Federal de Pelotas, Faculdade de Educação. Ano 16, no 28 jan/jun 2007. Páginas: 119-137. Pelotas, FaE/PPGE/UFPel. Disponível em: $<$ http://www.ufpel.edu.br/fae/caduc/institucional.htm>. Acesso em 12 mai. 2009 .

JIMENEZ, Susana. Consciência de classe ou cidadania planetária? Notas criticas sobre os paradigmas dominantes no campo da formação do educador. Educação. Vol.22. pp. 5772. Maceió, EDUFAL, 2005.

KOSIK, K. Dialética do concreto. Rio de Janeiro: Paz e Terra, 2002, 250 p. 
LABICA, G. As "teses sobre Fenerbach" de Karl Marx. Rio de Janeiro: Jorge Zahar Editor, 1987, 194 p.

LUKÁCS, G. Il Lavoro. In: Per una Ontologia dell' essere sociale. Roma: Riuniti, 1981. (Tradução Mimeogr. de Ivo Tonet).

Os princípios ontológicos fundamentais de Marx. In: Ontologia do ser social. São Paulo: Editora, Ciências Humanas, 1979. (Tradução Carlos Nelson Coutinho).

La Riproduzione. In: Per una Ontologia dell' essere sociale. Roma: Riuniti, 2009. (Tradução digitalizada de Marteana Ferreira de Lima).

MACENO, Talvanes E. (Im)Possibilidades e Limites da Universalização da Educação sob o Capital. Dissertação (Mestrado) - Programa de Pós-Graduação em Educação Brasileira, Universidade Federal de Alagoas. Maceió, 2005, 132 p.

MANACORDA, M. Alighiero. História da Educaşão: da Antiguidade aos nossos dias. São Paulo: Cortez, 2006, p. 382.

MARX, Karl. O Capital: Crítica da Economia Política. Livro 1, V. 1; São Paulo: Nova Cultural, 1985.

O Capital: Crítica da Economia Política. Civilização Brasileira: Rio de Janeiro, 2006, v. 1, livro primeiro, tomo 2, capítulo XXIV.

O Capital: Crítica da Economia Política. Livro 3, V. 6 Tomo 2, capítulo XLVIII. Civilização Brasileira: Rio de Janeiro, 2008.

MENDES SEGUNDO, M. das Dores. Educação Para Todos: A política dos organismos internacionais in: JIMENEZ, Susana; SOARES, Rômulo; DO CARMO, Maurilene, PORFÍRIO, Cristiane. Contra o Pragmatismo e a favor da filosofia da práxis: uma coletânea estudos classistas. Fortaleza, /EDUECE/IMO, 2007, 326 p.

MENDES SEGUNDO, M. das D. O Banco Mundial no Comando da Educação dos Países Periféricos. In: RABELO, J; FELISMINO, S. C et al (Orgs.). Trabalho, Educaşão e a Crítica Marxista. Fortaleza: Imprensa Universitária, 2006, 385 p.

MÉSZÁROS, I. O século XXI: socialismo on barbárie? São Paulo: Boitempo, 2003, $116 \mathrm{p}$. . A educação para além do capital. São Paulo: Boitempo, 2006, 77p. O Desafio e o Fardo do Tempo Histórico: o socialismo no século XXI. São Paulo: Boitempo, 2007, 396 p.

ORGANIZAÇÕES DAS NAÇÕES UNIDAS PARA A EDUCAÇÃO, CIÊNCIA E CULTURA - UNESCO. Declaração Mundial sobre Educação para 
Todos (Conferência de Jomtien). Tailândia: UNESCO, 1990. Disponível em: <www.unesco.org.br/publicacao/doc-internacionais>. Acesso em: 14 abr. 2008.

O Marco de Ação de Dakar Educação Para Todos: atendendo nossos Compromissos Coletivos. Dakar, Senegal: Cúpula Mundial de Educação, 2000c. Disponível em: <www.unesco.org.br/publicacao/docinernacionais/marcoDakar>. Acesso em: 14 jun. 2008.

TONET, Ivo. Educação, cidadania e emancipação humana. Ijuí: Ed. Unijuí, 2005, $251 \mathrm{p}$.

Educação contra o capital. Maceió: EDUFAL, 2007, 93 p. 